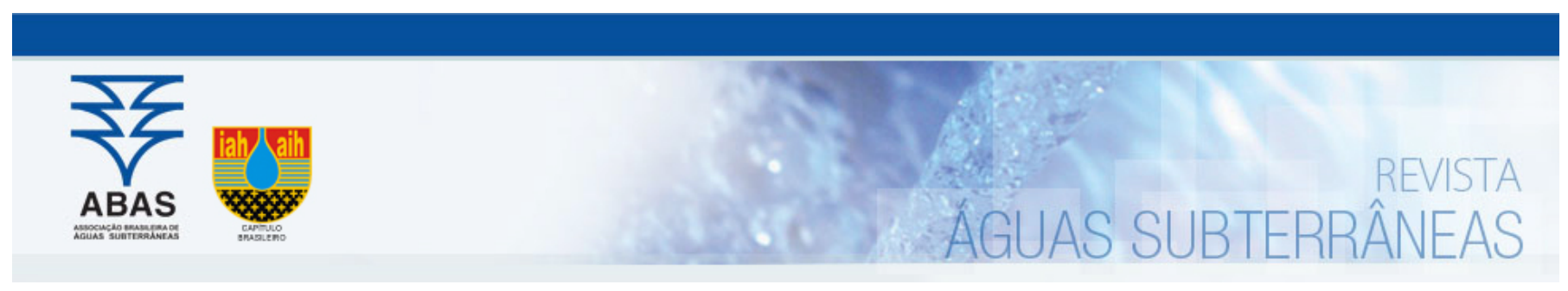

Artigos

\title{
Aplicação de técnicas direct push para caracterização litoestratigráfica de alta resolução em ambiente aluvionar
}

\section{Direct-push techniques applied to high-resolution lithostratigraphic characterization in alluvial environment}

\author{
Leandro Gomes de Freitas ${ }^{1}$; Marco Aurélio Zequim Pede 2 ; Hung Kiang Chang ${ }^{3} \bowtie$ \\ 1 IPT - Instituto de Pesquisas Tecnológicas do Estado de São Paulo, SP, Brasil. \\ 2 Fundação para o Desenvolvimento da UNESP-FUNDUNESP, São Paulo, SP, Brasil. \\ ${ }^{3}$ Laboratório de Estudos de Bacias - LEBAC/CEA/IGCE - Universidade Estadual Paulista (UNESP), Rio Claro, São Paulo, Brasil
}

Ifreitas@ipt.br ; mpede@yahoo.com ; chang@rc.unesp.br

\begin{tabular}{ll}
\hline & Resumo \\
\cline { 2 - 2 } & A aplicação de técnicas de investigação de alta resolução, com base em métodos Direct Push, para caracterização litoestrati- \\
Palavras-chave: & gráfica de áreas contaminadas, vem possibilitando a obtenção de modelos conceituais mais consistentes. Para avaliar a \\
Direct Push. & de Sação dessas técnicas em ambientes aluvionares, adotou-se como área de estudo o campus da USP Leste, no município \\
Caracterização litoestratigráfica. & com o sistema Soil Color Optical Screening Tool (SCOST) e amostragem de solo pelo método Dual Tube. Adicionalmente, \\
Investigação de alta resolução. & procedimentos laboratoriais foram adotados para caracterização granulométrica e análises do teor de matéria orgânica das \\
Áreas contaminadas. & amostras de solo. Os perfis obtidos em campo pelo MIP e pelo ScOST apresentaram boa correlação qualitativa com as descri- \\
Ambiente aluvionar. & ções litológicas e com os perfis granulométricos, refinando a caracterização litoestratigráfica. Já as análises do perfil de \\
& matéria orgânica mostraram a presença de camadas com elevado teor orgânico, indicando elevado potencial metanogênico, \\
& principalmente nas camadas de argilas e siltes orgânicos em meio aos sedimentos quaternários. As técnicas Direct Push \\
adotadas demonstram um grande potencial para a caracterização litoestratigráfica em alta resolução de ambientes aluviona- & res. \\
& Abstract
\end{tabular}

Keywords:

Direct Push.

Lithostratigraphic characterization. High resolution site characterization.

Contaminated sites.

Alluvial environment.

Revisado por pares.

Recebido em: 20/07/2017.

Aprovado em: 11/10/2017.

\begin{abstract}
The application of high resolution characterization tools, based on Direct Push methods, for the lithostratigraphic assessment of contaminated sites, has made it possible to obtain more consistent conceptual models. To evaluate the application of these techniques in alluvial environments, the USP Leste campus, located in São Paulo, was chosen for the present study. Three field techniques were analyzed: electrical conductivity (EC) of the MIP probe, Soil Color Optical Screening Tool (SCOST), and soil sampling with Dual Tube system. Additionally, laboratory procedures were adopted for grain size and organic matter content analyses of the soil samples. The profiles obtained with the MIP and SCOST showed a good qualitative correlation with the lithological descriptions and with the granulometric profiles, improving the lithostratigraphic characterization. Organic matter profile analysis showed presence of high organic content and high methanogenic potential layers, especially in the organic clay and silt layers of the Quaternary sediments. The Direct Push techniques demonstrated great potential for high resolution lithostratigraphic characterization of alluvial environments.
\end{abstract}

DOI: http://dx.doi.org/10.14295/ras.v31i4.28902

\section{INTRODUÇÃO}

A caracterização litoestratigráfica é uma atividade fundamental para os diagnósticos geoambientais. Tradicionalmente, essa etapa vinha sendo realizada somente por técnicas de sondagem para amostragem de solo e instalação de poços de monitoramento de água subterrânea, muitas vezes, ignorando os detalhes relacionados à heterogeneidade do meio físico.
Uma das questões em voga atualmente é a necessidade de ampliar a agilidade e a eficácia dos processos de investigações de áreas contaminadas, com vistas à elaboração de modelos conceituais mais precisos, que subsidiem tomadas de decisões assertivas para a reabilitação desses locais. Para isso, vem crescendo o uso de ferramentas de investigação de alta resolução, principalmente aquelas com base em métodos de cravação contínua (Direct Push). 
Os métodos Direct Push se difundiram inicialmente nos EUA, na década de 1990, mostrando uma melhor relação custo benefício em comparação às técnicas convencionais (BUTLER et al., 1999; USEPA, 2016). No Brasil, esses métodos vêm se popularizando, devido à praticidade e à qualidade agregada aos trabaIhos de campo, como no estudo apresentado por Riyis et al. (2013), que citam exemplos de diferentes técnicas aplicadas para obtenção de modelos conceituais em campo.

Uma série de dispositivos e sensores pode ser acoplada às hastes de cravação, tanto para coleta de amostras de solo, água subterrânea e gases, como para realização de ensaios hidráulicos ou para detecção de contaminantes in-situ. Dados geotécnicos, geofísicos, geoquímicos e hidrogeológicos podem ser obtidos, de modo contínuo ou pontual, por meio da cravação de sondas instrumentadas no subsolo. Além da agilidade, apresentam como vantagem adicional a minimização, ou até mesmo a eliminação, da geração de resíduos e efluentes, assim como a redução da exposição dos trabalhadores de campo aos contaminantes presentes. Quanto às limitações, destaca-se a restrição à perfuração de materiais resistentes ou consolidados, como argilas duras, rochas e concreções (USEPA, 2016).

Nesse contexto, o presente trabalho avaliou a aplicabilidade de diferentes métodos Direct Push, com auxílio de análises laboratoriais, para a caracterização litoestratigráfica de alta resolução de uma área contaminada em ambiente aluvionar.

\section{2 ÁREA DE ESTUDO}

A área de estudo se localiza no Campus da Universidade de São Paulo (USP), na zona leste da cidade de São Paulo - SP, sede da Escola de Artes, Ciências e Humanidades (EACH). O local corresponde a um antigo brownfield revitalizado na região de várzea do rio Tietê. Segundo o Relatório Ambiental Preliminar RAP (COSTA, 2004), o terreno começou a ser aterrado na década de 1970, sendo utilizado como bota-fora para materiais de dragagem do rio Tietê nas décadas de 1980 e 1990. Dados de sondagens geotécnicas mostraram que tais depósitos possuem espessura aproximada de $5 \mathrm{~m}$, sendo compostos, predominante mente, por areia, com camadas de materiais finos, com presença de matéria orgânica abundante, e ocorrências de materiais antrópicos, como plásticos, garrafas e pneus. Ainda segundo o estudo, a implantação do Campus adotou apenas obras de corte e aterro, sem a utilização de materiais de empréstimo.

No contexto geológico, a área se localiza na planície aluvial do Rio Tietê, formada por sedimentos quaternários depositados sobre os sedimentos paleogênicos da Formação Resende, pertencentes à Bacia Sedimentar de São Paulo (BSP). Os sedimentos quaternários são compostos por argilas, areias, cascaIhos e niveis de seixos, em geral, com granodecrescência ascendente. Quanto aos sedimentos paleogênicos, localmente predominam lamitos de leques aluviais medianos a distais, e areias e conglomerados de sistemas fluviais entrelaçados (RICCOMINI et al., 2004). O aquífero local é caracterizado como livre, de porosidade primária, heterogêneo e anisotrópico, associado aos sedimentos quaternários e também aos materiais de aterro sobrejacentes. Este aquífero pode apresentar uma espessura média de até dezenas de metros, conectando-se hidraulicamente com os sedimentos terciários da BSP (VARNIER \& HIRATA, 2002).

O local selecionado para os ensaios foi um setor não edificado, com histórico de estudos técnicos e acadêmicos relacionados à contaminação e à ocorrência de gás metano no subsolo (Figura 1). Conforme os trabalhos realizados por IPT (2011) e Servmar (2014), não foram detectados contaminantes orgânicos nas amostras coletadas no local, apenas substâncias inorgânicas (metais e íons maiores), nas fases adsorvida e/ou dissolvida no aquífero. Mendonça et al. (2015) apresentaram a combinação de levantamentos geofísicos com amostragens de solo, água subterrânea e gases do solo. Os resultados subsidiaram a elaboração de um modelo conceitual da área, possibilitando a delimitação das principais camadas litológicas e a identificação de bolsões de biogás em três diferentes níveis do subsolo. 
Figura 1 - Localização da área de estudos e posição dos pontos de investigação (clusters), com a distribuição espacial dos ensaios executados em cada um

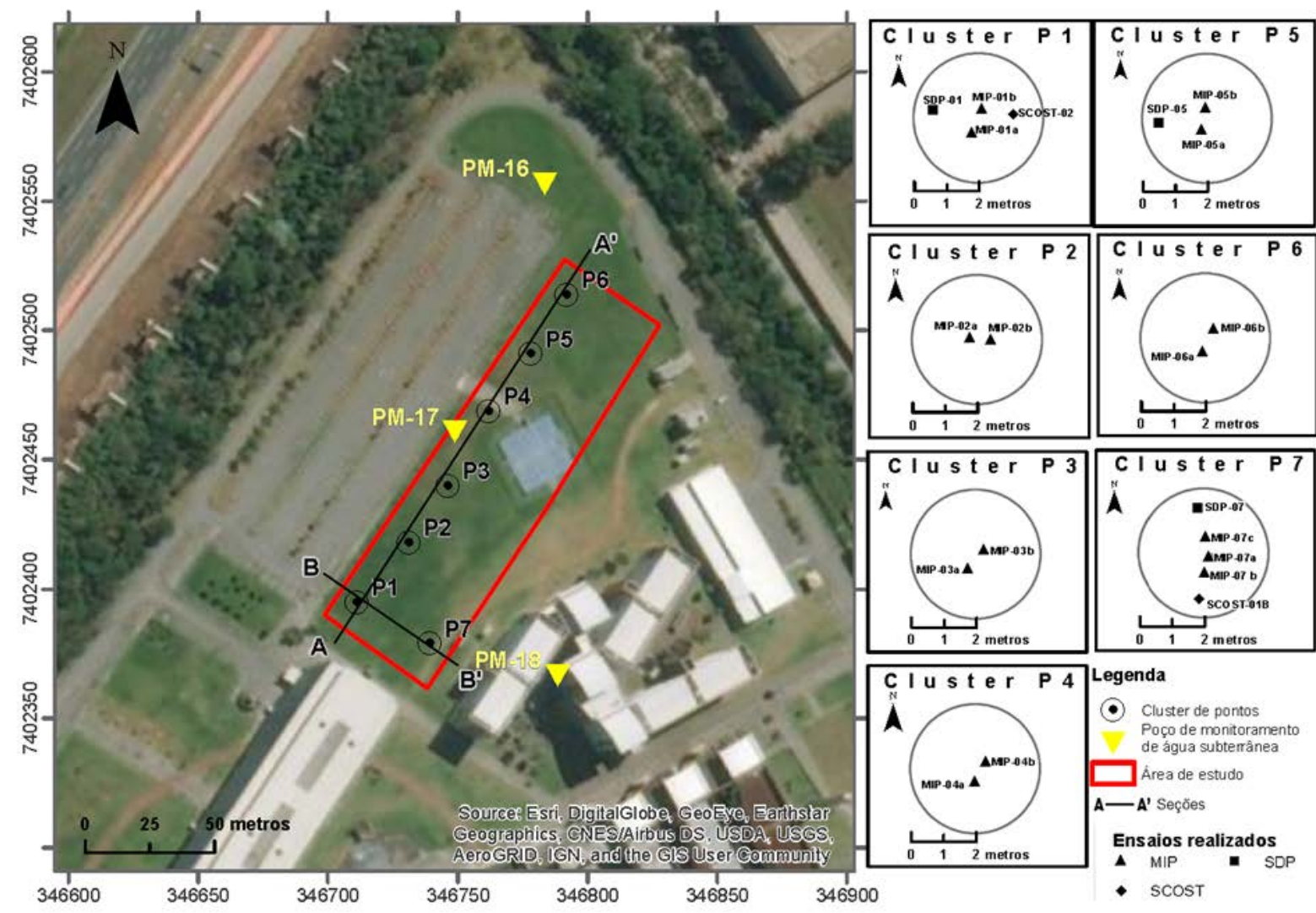

\section{MATERIAIS E MÉTODOS}

Os métodos Direct Push adotados em campo para a caracterização litoestratigráfica foram: ensaios com o sensor de Condutividade Elétrica (EC) da sonda Membrane Interface Probe (MIP); ensaios com o sistema Soil Color Optical Screening Tool (SCOST) e amostragens contínuas de solo por sondagens Direct Push (SDP). Adicionalmente, foram medidos os níveis d'água subterrânea (NAs) em poços de monitoramento (PMs) préexistentes nas proximidades.

Os ensaios foram agrupados em "Clusters", de forma que cada grupo representasse um mesmo "ponto" de investigação, possibilitando a comparação dos resultados. A localização dos clusters é apresentada na Figura 1.

\subsection{Sensor de condutividade elétrica da sonda MIP}

O sensor de condutividade elétrica (EC) corresponde a um conjunto de eletrodos que mede a resposta do solo à injeção de corrente elétrica. Essa resposta é medida em mili-Siemens por metro (mS/m). Segundo Christy (1996), a principal função desse sensor é auxiliar na caracterização litoestratigráfica do subsolo. Schulmeister et al. (2003) afirmam que, devido ao contraste no comportamento elétrico, camadas predominantemente arenosas ou argilosas podem ser mapeadas por meio do sensor de EC. Por fornecer dados continuamente, a cada 1,5 $\mathrm{cm}$ de cravação, essa ferramenta é considerada uma das mais importantes para investigações geoambientais de alta resolução. Diversos trabalhos destacam ainda seu potencial para caracterização de ambientes heterogêneos e estratificadas, como os depósitos aluvionares (MCCALL, 1996; Butler et al., 1999; WILSON et al., 2005).
No presente estudo, o sensor EC, acoplado à sonda MIP, possuía um arranjo dipolo, considerado razoavelmente preciso para medições na faixa de 5 a 400 mS/m (CHRISTY, 1996). Foram executados 15 ensaios, em sete pontos de investigação (P1 a $\mathrm{P} 7$ ), com distância de $30 \mathrm{~m}$ entre cada ponto, de modo a compor 2 seções ortogonais, conforme apresentado na Figura 1. A priori, as repetições dos ensaios foram executadas com o intuito de avaliar a resposta do detector de ionização por chama (FID), do sistema MIP, a diferentes condições de operação, com vistas à detecção e mapeamento de metano no subsolo. No entanto, as respostas do detector FID não são objeto do presente artigo. Com relação ao sensor EC, foi possível tratar essas repetições como réplicas dos ensaios.

Antes do início e após a finalização de cada ensaio, foram realizados os testes de resposta dos sensores. Os resultados foram visualizados em tempo real e, posteriormente, foram tratados com o software DI Viewer da empresa Geoprobe.

\subsection{Sistema Soil Color Optical Screening Tool}

O sistema SCOST é um módulo complementar do equipamento UVOST (Ultra-Violet Optical Screening Tool), fabricado pela empresa Dakota Technologies Inc. A ferramenta se destina, essencialmente, a promover uma perfilagem contínua, de alta resolução, das cores do solo, em função da profundidade do ensaio.

No estudo, foram definidos dois locais de execução, os pontos $\mathrm{P} 7$ e o $\mathrm{P} 1$, onde foram realizados, respectivamente, os ensaios SCOST-01b e SCOST-02, conforme apresentado na Figura 1. Antes de iniciá-los, foram realizados os testes de resposta e a calibração do sistema, conforme as recomendações do fabricante. 
Durante os ensaios, a velocidade de cravação empregada foi de, aproximadamente, $2 \mathrm{~cm} / \mathrm{s}$. A profundidade máxima atingida foi de $10,39 \mathrm{~m}$, limitada pela resistência dos materiais perfurados.Os resultados foram processados pelo software Optical Screening Tool PRO. Posteriormente, foram comparados com a Carta de Munsell para a delimitação das principais camadas, buscando-se correlacioná-los com possíveis características geoquímicas do subsolo, bem como com as interpretações litoestratigráficas obtidas pelo sensor EC da sonda MIP.

\subsection{Amostragem de solo por sondagens Direct Push}

A amostragem de solo por sondagens SDP é um método tradicional de investigação geoambiental, tanto para caracterização litoestratigráfica, como para obtenção de amostras para análises químicas e físicas, sendo uma etapa fundamental na elaboração do modelo conceitual de áreas contaminadas.

Existem, basicamente, duas categorias de sistemas Direct Push: os sistemas com tubo único (Single Tube) e os sistemas com tubo duplo (Dual Tube). O Dual Tube é considerado um método superior ao Single Tube, pois o furo de sondagem fica protegido e selado por um revestimento externo durante a execução, evitando a potencial contaminação cruzada das amostras de solo e possibilitando amostragens contínuas, inclusive na zona saturada (ASTM, 2014).

No presente estudo, a amostragem de solo foi realizada visando a caracterização do perfil litológico e a obtenção de amostras para a realização de análises laboratoriais. Adicionalmente, realizou-se a comparação com os resultados das demais técnicas, de modo a possibilitar uma melhor interpretação dos dados. O sistema utilizado foi o Dual Tube, com diâmetros externos de $57,15 \mathrm{~mm}$ e $82,55 \mathrm{~mm}$.

Os locais de execução foram definidos a partir dos resultados das sondas MIP e SCOST, buscando-se selecionar pontos representativos da área de estudo. Foram executadas três sondagens (SDP-01, SDP-05 e SDP-07), respectivamente, nos clusters $\mathrm{P} 1$, P5 e P7, conforme apresentado na Figura 1. A profundidade das sondagens avançou até aproximadamente 10,5 m, quando não foi mais possível prosseguir, devido à resistência dos materiais perfurados. Todos os amostradores liners foram devidamente identificados e encaminhados para caracterização no Laboratório de Estudo de Bacias (LEBAC) da UNESP Rio Claro.

\subsection{Descrição táctil visual e coleta de amostras para análises laboratoriais}

Os liners foram abertos em bancada para a realização das descrições táctil visuais das amostras de solo e para a definição dos perfis litoestratigráficos, representados segundo a simbologia estabelecida pela ABNT. Adicionalmente, 111 sub-amostras de solo foram coletadas para caracterização laboratorial, das quais 70 foram encaminhadas para análise granulométrica e 41 foram para análise do teor de matéria orgânica. Os resultados foram tabelados e apresentados na forma de perfis.

\subsection{Processamento e apresentação dos dados}

Os resultados foram tratados pelos softwares DI Viewer, Microsoft Excel e Power Point, tanto para montagem dos perfis e seções representativas do subsolo, como para análise dos dados. Além da comparação com os resultados do sensor EC, os perfis de cores do SCOST foram confrontados com os resultados obtidos nos ensaios laboratoriais, auxiliando na caracterização litoestratigráfica. A análise integrada dos dados, bem como a comparação com outros estudos anteriormente executados no local, subsidiou a elaboração do modelo conceitual da área.

\section{RESULTADOS E DISCUSSÃO}

\subsection{Sensor de condutividade elétrica da sonda MIP}

A interpretação dos perfis do sensor EC foi realizada buscandose identificar feições características, associáveis às principais camadas do subsolo, por meio de uma inferência qualitativa de suas características físicas (textura), e pela comparação com perfis descritos de estudos anteriores. As classes e critérios utilizados foram:

Tabela 1 - Classes e critérios utilizados na interpretação dos ensaios do sensor EC

\begin{tabular}{cl}
\hline Classe & \multicolumn{1}{c}{ Critérios } \\
\hline Grossa & $\begin{array}{l}\text { Texturas granulares grossas (areias, areia siltosa, cascalhos e seixos), definidas por CE } \leq 35 \mathrm{mS} / \mathrm{m} \text { (aproxi- } \\
\text { madamente) e feições geralmente côncavas no sentido crescente do perfil do sensor EC. }\end{array}$ \\
Fina & $\begin{array}{l}\text { Texturas granulares finas (argila, silte, argila siltosa, argila arenosa e silte arenoso), definidas por CE }>35 \\
\mathrm{mS} / \mathrm{m} \text { (frequentemente }>50 \mathrm{mS} / \mathrm{m} \text { ) e feições convexas no sentido crescente do perfil do sensor EC. }\end{array}$ \\
Intercalações & $\begin{array}{l}\text { Camadas com oscilações curtas do sinal do sensor EC, envolvendo variações de categoria e geralmente } \\
\text { associadas com texturas intermediárias (e.g. areia fina siltosa, silte arenoso, areia argilosa etc.). }\end{array}$ \\
& $\begin{array}{l}\text { Camadas com variações graduais, ou menos abruptas, do sinal do sensor EC, envolvendo transições entre } \\
\text { Transições }\end{array}$ \\
& $\begin{array}{l}\text { Aumento, geralmente abrupto, do sinal do sensor EC, associado à mudança litológica, com a penetração da } \\
\text { serciário }\end{array}$ \\
\hline
\end{tabular}


Adicionalmente, inseriu-se o NA aproximado de cada ponto, obtido pelas médias das medições realizadas nos poços de monitoramento mais próximos.

Ao comparar os ensaios em duplicata, o coeficiente de correlação $(R)$ variou entre 0,71 (EC/P3) a 0,96 (EC/P2), evidenciando uma forte correlação e a reprodutibilidade dos ensaios, apesar das heterogeneidades do subsolo.

As categorias estabelecidas mostraram-se condizentes com o modelo conceitual de estudos anteriores, possibilitando interpretações coerentes. As feições identificadas, comuns a praticamente todos os perfis, foram: a camada de textura fina, entre as profundidades médias de 4,8 a $7,0 \mathrm{~m}$; a camada de textura grossa, entre 8,6 e 10,2 m; e, o aumento abrupto do sinal, por volta de 10,2 m. Essas feições estão associadas a possíveis "marcos estratigráficos" da área, sendo fundamentais na interpretação dos resultados, conforme apresentado na seção esquemática A-A', da Figura 2.

As camadas superficiais, até uma profundidade aproximada de 4,8 m, foram associadas com os depósitos tecnogênicos (DTec), referentes aos materiais de dragagem. Esses materiais apresentam uma característica de alternância entre texturas finas e grossas, bem como a presença da camada de "intercalações", associada com variações texturais frequentes. O limite inferior, entre os DTec e os sedimentos quaternários (SQa), não pode ser definido com precisão em alguns pontos, pois a composição dos materiais é muito parecida, gerando comportamentos elétricos similares e/ou confusos. Essa característica pode ser atribuída à origem comum dos materiais, associados aos sedimentos de várzea do Rio Tietê.

A camada de textura fina, identificada em todos os ensaios, abaixo dos DTec, foi associada à fácies argilosa dos sedimentos quaternários (SQa-FArg). Essa camada apresenta formato convexo e bastante irregular nos perfis, com espessuras de até 2,8 m (e.g. EC/P3b), se destacando das camadas adjacentes por apresentar EC geralmente acima de $50 \mathrm{mS} / \mathrm{m}$, podendo ultrapassar $100 \mathrm{mS} / \mathrm{m}$. Encontra-se delimitada em profundidade por uma transição relativamente gradual para camada de textura grossa, caracterizada pelo formato côncavo no perfil do EC.

Na maioria dos ensaios, foi identificada uma camada intermediária, denominada "transição", associada à mudança litológica da fácies argilosa (FArg) para a fácies arenosa (FAre) dos SQa. Outros métodos de caracterização (e.g. análises granulométricas) foram necessários para definir as texturas dessa camada.

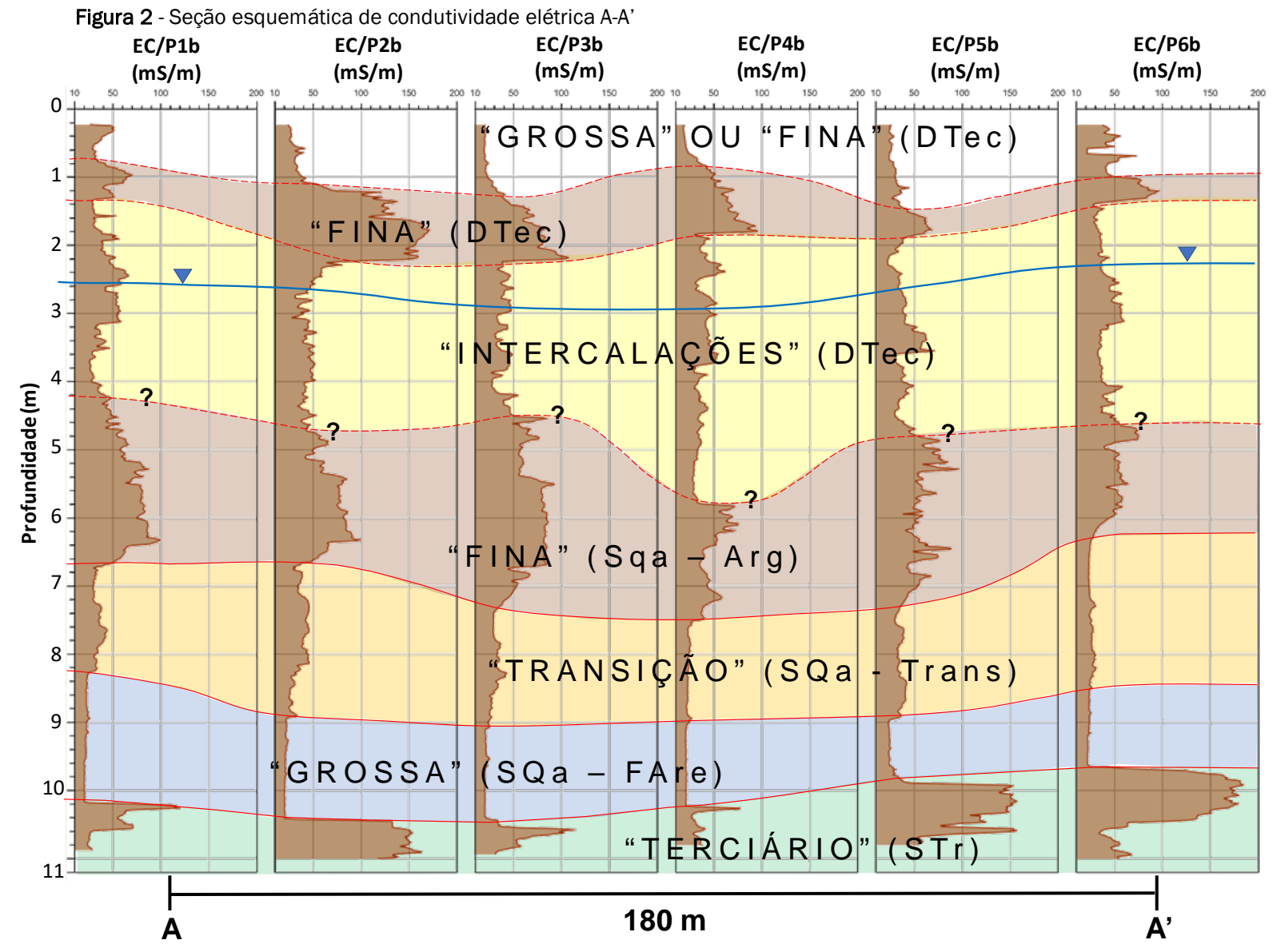

Com relação à camada de textura grossa, identificada em todos os ensaios, foi associada à fácies arenosa que compõe a base dos SQa (SQa-FAre). Essa camada apresenta uma feição elétrica relativamente homogênea, com valores de CE na faixa de 20 a $25 \mathrm{mS} / \mathrm{m}$, podendo apresentar espessuras de até 2,7 m (e.g. EC/P4b). Seu limite em profundidade se dá pelo aumento, geralmente abrupto, no perfil do EC, associado à mudança litológica para os sedimentos terciários (STr).

Essa última camada, denominada "terciário" nos perfis, apresenta feições elétricas "tabulares" abruptas, mais ou menos delgadas, com EC geralmente ultrapassando $100 \mathrm{mS} / \mathrm{m}$, po- 
dendo chegar a $190 \mathrm{mS} / \mathrm{m}$ (e.g. EC/P6a). Na maioria dos pontos, abaixo das "lentes" superficiais de textura fina, ocorrem intercalações para texturas grossas, evidenciadas por diminuições abruptas no sinal do EC. Essas camadas mostraram-se altamente resistentes à penetração da sonda MIP.

Apesar das interpretações coerentes, sabe-se que outros fatores, além da textura dos materiais, podem influenciar nos resultados do sensor EC. Dessa forma, as interpretações foram comparadas e validadas com outras técnicas, conforme as recomendações apresentadas por Schulmeister et al. (2003), entre outros autores.

\subsection{Sistema SCOST}

Os perfis de cores do solo, obtidos pelo sistema SCOST, possibilitaram a delimitação das principais camadas litológicas, conforme apresentado na Figura 3.

As cores predominantes foram as cinzentas, de matizes neutras, principalmente GLEY 2, com cinzas escuros ou azulados, intercaladas com matizes 5R, 7.5R, 5YR, 7.5YR, 10YR, de tonalidades cinza amarronzadas ou avermelhadas e cinza escuro. A Tabela 2 apresenta um resumo dos padrões de cores das principais camadas litológicas, conforme a comparação com a Carta de Munsell.

Figura 13 - Perfil do ensaio SCOST-02, com a delimitação das principais camadas

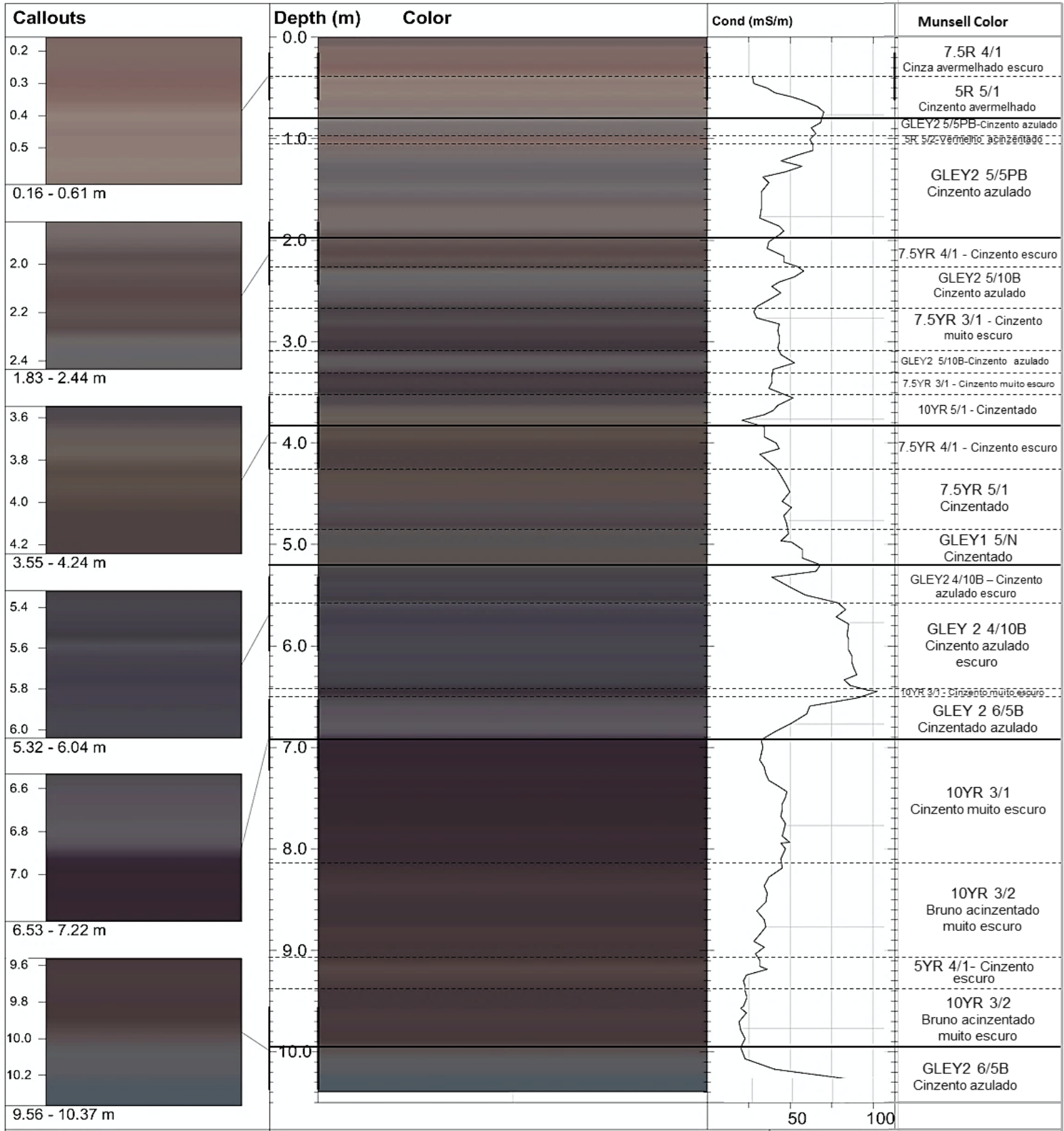


Tabela 2 - Principais camadas e padrões de cores conforme a Carta de Munsel

\begin{tabular}{cl}
\hline $\begin{array}{c}\text { Profundidade média } \\
\text { das camadas }(\mathrm{m})\end{array}$ & \multicolumn{1}{c}{ Padrões de cores conforme a Carta de Munsell } \\
\hline 0,0 a 0,8 & $\begin{array}{l}\text { Cores avermelhadas, matiz 5R a 7,5R, entre cinza avermelhado escuro (valor 4 e croma 1) a vermelho } \\
\text { acinzentado (valor 4 e croma 2). } \\
\text { Intercalações de tonalidades cinza, matizes GLEY 2; 7,5R; 7,5YR e 10YR, variando entre azulado e aver- } \\
\text { melhado, geralmente com valores (brilho) intermediários, entre 4 e 6. }\end{array}$ \\
5,8 a 5,5 a 7,6 & $\begin{array}{l}\text { Espessa camada de matiz GLEY 2, de cor cinza azulada e brilho entre 4 e 5, intercalada com uma fina } \\
\text { camada cinzenta muito escura (10YR 3/1). } \\
\text { Espessa camada de cor cinzenta azulada escura a cinzenta muito escura, com valores entre 3 e 4, mati- } \\
\text { zes GLEY 2 e 10YR. }\end{array}$ \\
8,4 a 10,0 & $\begin{array}{l}\text { Camadas espessas de cores bruno acinzentadas, matizes 10YR e 5YR, com valores variando entre 4 e 3 } \\
\text { (escuro a muito escuro) e croma entre 1 e 2. } \\
\text { Transição bastante nítida, por volta de 10,0 m de profundidade, para uma cor cinzenta azulada (GLEY 2), } \\
\text { com brilho 6 e croma 5B. }\end{array}$ \\
\hline
\end{tabular}

Essa análise mostrou uma forte correlação qualitativa com os perfis elétricos da sonda MIP, possibilitando, mesmo que de modo aproximado, correlacionar as camadas de cores com as feições litológicas da área de estudo.

Neste contexto, as camadas superficiais, de cores cinza avermelhadas, e as camadas intercaladas abaixo, de cores cinza azuladas, avermelhadas e cinza escuras, até a profundidade média de $5,5 \mathrm{~m}$, podem ser associadas com as camadas de materiais de dragagem (DTec), enquanto que a camada abaixo, de cor cinza azulada escura, até a profundidade média de 7,5 $\mathrm{m}$, pode ser associada com a fácies argilosa dos SQa. No entanto, assim como nos perfis de EC, o limite entre esses estratos não pode ser definido com clareza, devido à origem comum dos materiais e por estarem sujeitos ao mesmo ambiente hidrogeoquímico.

As camadas delimitadas entre 7,5 e $10,0 \mathrm{~m}$, de cores cinzento escuro a muito escuro e bruno acinzentado muito escuro, podem ser associadas às feições elétricas denominadas "transição" e "grossa" nos perfis de CE, relacionadas à fácies arenosa dos SQa. Abaixo de $10 \mathrm{~m}$ de profundidade, a cor cinzenta azulada (mais clara) foi nitidamente atribuída aos STr.

Segundo CA-EPA (2012), a caracterização das cores do solo pode ser utilizada para identificação de solos hidromórficos, possibilitando inferir sobre suas condições de drenagem e estado de oxirredução, bem como para identificação de camadas ricas em matéria orgânica. Neste contexto, os perfis do SCOST indicam, já no primeiro metro de sondagem, um incremento nas condições redutoras, marcado pela transição de camadas avermelhadas (provavelmente devido à presença de oxigênio), para uma sequência litológica de cores cinzentas a bruno acinzentado, mais ou menos escuras. Adicionalmente, a presença de tons escuros, principalmente nas camadas abaixo de $5,5 \mathrm{~m}$, pode ser um indicativo de maiores concentrações de MO nos SQa, o que pode favorecer processos metanogênicos.

\subsection{Descrições litológicas e resultados das análises laboratóri- ais}

$\mathrm{Na}$ amostragem de solos por SDP, alguns liners apresentaram defasagem de recuperação dos testemunhos. A taxa de recuperação média foi $91 \%$ nos de maior diâmetro e $84 \%$ nos de menor diâmetro.
Para mitigar esse problema, as descrições táctil-visuais foram posteriormente comparadas com os perfis elétricos, obtidos pela sonda MIP, e com os perfis de cores do SCOST, possibilitando a correção de eventuais incertezas na definição da litoestratigrafia da área. Com base nessas correções, adequaram-se também as profundidades das amostras enviadas para caracterização laboratorial.

A Figura 4 apresenta o resultado das análises de granulometria acumulada e teor de matéria orgânica dos pontos SDP-01, SDP05 e SDP-07, na forma de perfis.

As análises granulométricas auxiliaram na correção e no refinamento da caracterização litoestratigráfica, confirmando a categorização das feições elétricas dos perfis do sensor EC. A exceção se deu apenas para a camada denominada "Transição" nos perfis elétricos, localizada entre 7,5 e 8,5 m nos SQa, pois, apesar da predominância de texturas finas (argila siltosa e silte argiloso), as leituras do EC foram relativamente baixas (ECmédio $40 \mathrm{mS} / \mathrm{m})$. Uma possível causa está nos elevados teores de MO detectados nessa camada, conferindo um caráter mais resistivo do que o esperado para tais texturas. Para as demais camadas, o EC apresentou uma forte correlação com a textura dos materiais.

Os teores de MO nas amostras de solo variaram entre 0,36\% e $26,06 \%$. Segundo o IAC (2017), solos finos tendem a apresentar maiores concentrações de MO em comparação com solos grossos, com valores acima de $6 \%$ indicando teores elevados por condições localizadas (e.g. má drenagem). Os resultados obtidos concordam com essa referência, pois teores elevados de $\mathrm{MO}(>6 \%)$ foram obtidos nas amostras de textura fina, tanto em meio aos DTec (entre 1,1 e 3,5 m), como nas camadas de siltes e argilas orgânicas dos SQa (entre 4,8 e 8,8 m), onde foram obtidos os maiores valores.

Com base nesses resultados, pode-se inferir que a camada de solos orgânicos, em meio aos SQa, possui um elevado potencial metanogênico. Camadas de silte argilosos em meio aos DTec também apresentam potencial teórico, devido aos elevados teores de MO. No entanto, deve-se considerar que esta é apenas uma análise qualitativa, pois outros parâmetros devem ser avaliados para se determinar o potencial metanogênico dessas camadas (e.g. parâmetros microbiológicos, grau de degradação da MO, parâmetros hidrogeoquímicos do meio etc.). 
Figura 4 - Perfis de granulometria (coloridos) e teor de matéria orgânica (linhas e pontos pretos) das amostras de solo

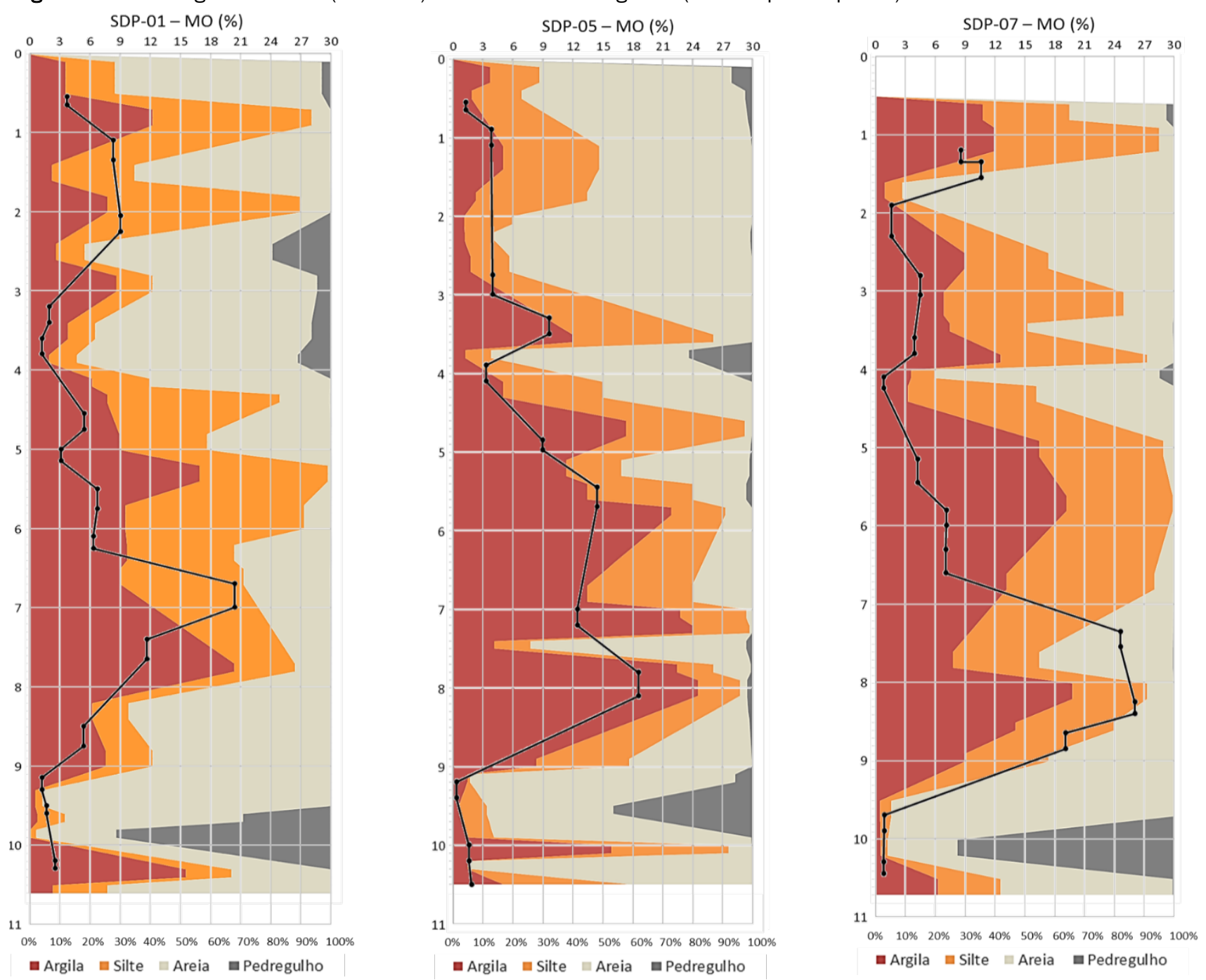

\subsection{Análise integrada dos resultados e definição do modelo conceitual}

Os perfis obtidos foram emparelhados e comparados, fornecendo diversas linhas de evidência em alta resolução para uma análise integrada, visando a caracterização do perfil litoestratigráfico da área de estudo. A Figura 5 apresenta como exemplo a integração realizada no Cluster P1.

O modelo conceitual obtido mostra a presença da camada de depósitos tecnogênicos (DTec), composta pelos materiais de dragagem, até uma profundidade média de 4,2 m. Esses depósitos são compostos por uma camada superficial de $0,8 \mathrm{~m}$, de textura silte arenoso ou areia siltosa, localmente argilosa, sobreposta a uma camada silte argilosa de até 1,0 m de espessura, a partir da qual já se observam indícios de um ambiente geoquímico redutor, em função da presença abundante de restos orgânicos e das cores cinzentas (matiz "gley"). Logo abaixo, observa-se uma sequência de camadas intercaladas de areias siltosas com silte argilosos e silte arenosos, geralmente com presença de cascalhos entre 3,0 e 4,0 m de profundidade, apresentando tonalidades cinzentas e amarronzadas escuras, com frequente presença de resíduos plásticos e restos vegetais.
A passagem da camada de aterro para o substrato natural (antiga várzea) é marcada pela elevação na quantidade de materiais finos (argila e silte) e pela elevação dos valores de condutividade elétrica, assim como pela ocorrência de intervalo rico em restos vegetais na base. Essa camada de finos corresponde à fácies argilosa dos sedimentos quaternários (SQa-Arg), com espessuras de 2,0 a 4,0 m, localmente com lentes mais arenosas, apresentando colorações cinza escuro a muito escuro, associadas com argilas e siltes orgânicos e um aumento gradual nos teores de MO.

Logo abaixo, verifica-se a continuidade da camada de argila orgânica, com espessuras de 1 a $2 \mathrm{~m}$, com eventuais lentes de turfa, marcada principalmente pela cor cinzenta muito escura e pela abundância de MO (teores superiores a $26 \%$ ), mas que apresenta respostas elétricas relativamente baixas ( $<40 \mathrm{mS} / \mathrm{m}$ ), devido ao caráter resistivo da MO. Essa camada, denominada "SQa-Trans", apresenta um aumento dos níveis de areia em profundidade, exibindo uma transição ora gradual, ora abrupta, por volta de 8,5 a 9,0 m, para uma camada de predominância arenosa, associada à fácies arenosa dos SQa (SQaAre). Essa camada arenosa é constituída por areia fina a média, passando a areia grossa e uma linha de seixos, por volta $10 \mathrm{~m}$ de profundidade. 
Abaixo da linha de seixos, por volta de 10,2 m, as sondagens atingiram um estrato altamente resistente à perfuração pelos métodos Direct Push, onde, observa-se um brusco aumento no sinal do sensor EC. Essa camada corresponde aos sedimentos paleogênicos da Formação Resende, compostos por lentes de argila siltosa intercaladas com areias siltosas, de cor cinza esverdeado.
Este modelo conceitual se assemelha ao proposto por Mendonça et al. (2015), tanto na definição da litoestratigrafia local, como na identificação de potenciais camadas geradoras de metano em subsuperfície. No entanto, os métodos aqui utilizados fornecem resultados com melhor resolução vertical, possibilitando um refinamento do modelo conceitual litoestratigráfico.

Figura 5 - Integração dos perfis dos ensaios realizados no cluster P1

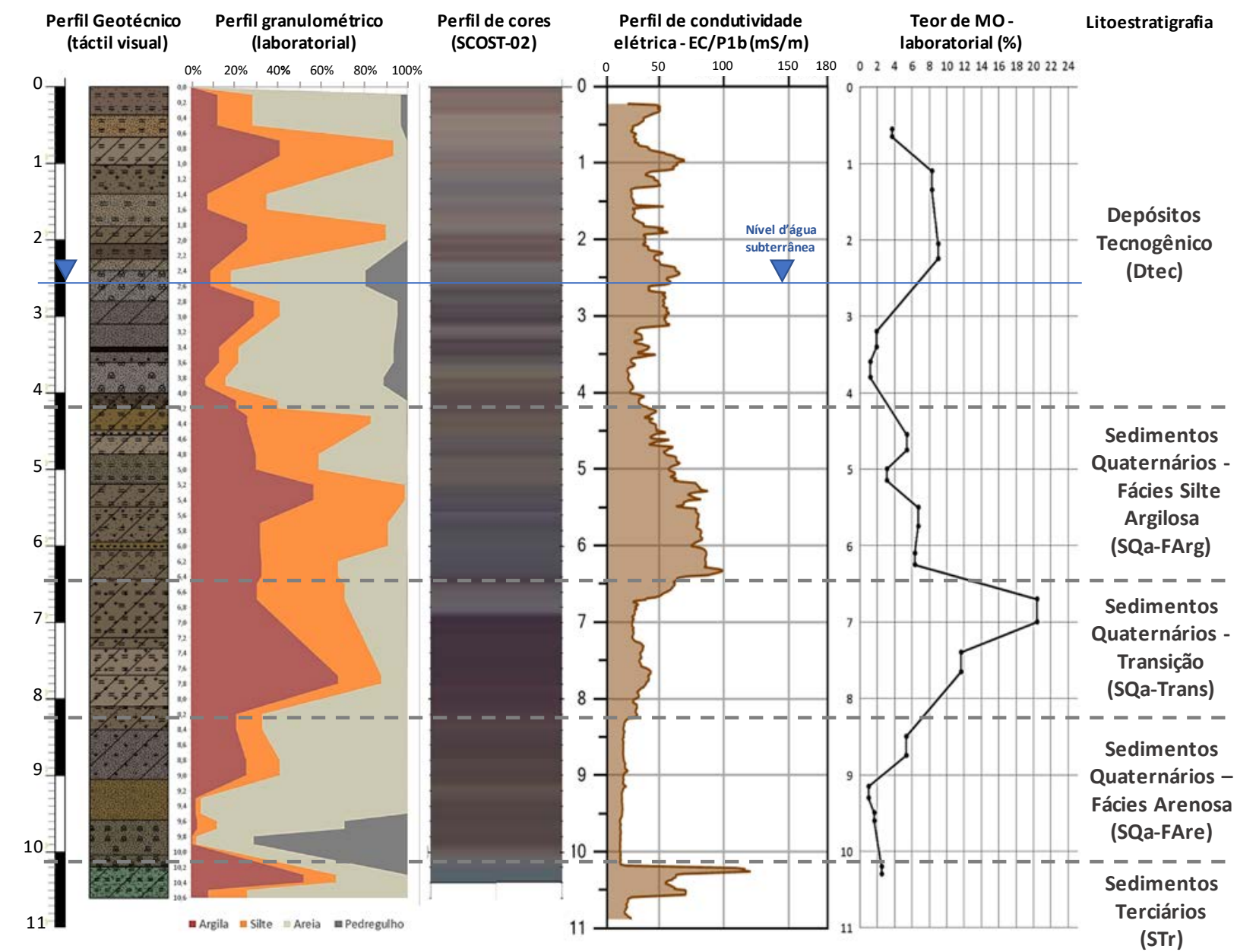

\section{CONCLUSÕES}

As técnicas Direct Push adotadas possibilitaram a obtenção de um grande volume de dados, com alta resolução vertical, para a caracterização litoestratigráfica da área de estudo. Os resultados do sensor EC possibilitaram o estabelecimento de correlações semiquantitativas entre as respostas elétricas e a litologia do subsolo. Essas correlações foram confirmadas pelas descrições e análises laboratoriais de amostras de solo coletadas nas mesmas camadas.

Os ensaios com o sistema SCOST forneceram perfis de cores e perfis elétricos de alta resolução, auxiliando na distinção das camadas sedimentares e fornecendo indícios das condições geoquímicas do subsolo.

A amostragem de solo pelo método Direct Push mostrou-se fundamental para caracterização litológica e para apoiar a interpretação e validação dos resultados das demais técnicas.
Os perfis de MO permitiram identificar camadas com altos teores orgânicos, indicando um elevado potencial metanogênico. Essas camadas se localizam, principalmente, em materiais de textura fina, em meio aos materiais de dragagem e nas camadas de siltes e argilas orgânicas dos sedimentos quaternários. No entanto, para uma caracterização quantitativa do potencial metanogênico, um estudo hidrogeoquímico mais abrangente deve ser realizado.

Os resultados corroboram estudos anteriormente realizados no local, mostrando que a metodologia hora proposta pode contribuir para o refinamento dos modelos conceituais preestabelecidos.

Por fim, ressalta-se que o estudo foi realizado em um contexto geológico bastante específico, relacionado à caracterização de um ambiente aluvionar. Dessa forma, recomenda-se a realização de estudos semelhantes em outras áreas, de forma que a metodologia proposta possa ser testada e adaptadas para diferentes contextos geológicos e de contaminação do subsolo. 


\section{REFERÊNCIAS}

AMERICAN SOCIETY OF TESTING MATERIALS. ASTMD6282/D6282M 14. Standard Guide for Direct Push Soil Sampling for Environmental Site. West Conshohocken, PA, 2014. 20 p.

BUTLER, J. J. et al. Hydrostratigraphic characterization of unconsolidated alluvial deposits with direct-push sensor technology. Kansas. $1999 . \quad$ Disponivel em: <http://www.kgs.ku.edu/Hydro/Publications/OFR99_40/index.html>. Acesso em: 10 set. 2015.

CALIFORNIA ENVIRONMENTAL PROTECTION AGENCY - CA-EPA. 2012. Evaluation of biogenic methane. A Guidance Prepared for the Evaluation of Biogenic Methane in Constructed Fills and Dairy Sites. Disponivel em: <https://www.dtsc.ca.gov/PublicationsForms/upload/BF_Schools_Eval _of_Biogenic_Methane_March_2012.pdf>.Acesso em: 30 nov. 2016.

CHRISTY, T. M. A drivable permeable membrane sensor for detection of volatile compounds in soil. In:10 th National Outdoor Action Conference. Anais... Las Vegas, Nevada: NGWA, 1996.

COSTA, W.M (Coord. Geral). Relatório Ambiental preliminar-RAP- Campus USP Leste. São Paulo: USP, Prefeitura do Campus da Capital, 2004. 176 p. e anexos.

HAUSMANN, J. et al. Technique, analysis routines, and application of direct push-driven in situ color logging. Environmental Earth Sciences, v. 75, n. 11, p. 957, jun. 2016.

INSTITUTO AGRONÔMICO DO ESTADO DE SÃO PAULO - IAC. Informação Sobre Interpretação de Análise de Solo. Centro de Pesquisa e Desenvolvimento de Solos e Recursos Ambientais. Campinas: IAC, 2017. Disponível em:

http://www.iac.sp.gov.br/produtoseservicos/analisedosolo/interpretaca oanalise.php>. Acesso em: 05 jan. 2017.

INSTITUTO DE PESQUISAS TECNOLÓGICAS DO ESTADO DE SÃO PAULO IPT. Relatório Final - Investigação do Subsolo da Gleba I do Campus da EACH/USP para Avaliação de Risco da Saúde Humana e Complementação da Investigação das Áreas de Implantação do Ginásio de Esportes. RT 123.582-205/11. São Paulo, SP. 2011.

MCCALL, W. Electrical Conductivity Logging to Determine Control of Hydrocarbon Flow Paths in Alluvial Sediments. In:10th National Outdoor Action Conference. Anais...Las Vegas, Nevada, 1996. Disponível em: <http://files.geoprobe.com/pdfs/ condpaperwes_0.pdf>. Acesso em: 20 fev. 2016.

MENDONCA, C. A. et al. Integrated earth resistivity tomography (ERT) and multilevel sampling gas: a tool to map geogenic and anthropogenic methane accumulation on brownfield sites. Environmental Earth Sciences, v. 74, n. 2, p. 1217-1226, 2015.

RICCOMINI, C.; SANT'ANNA, L. G.; FERRARI, A. L. Evolução geológica do Rift Continental do Sudeste do Brasil. In: MANTESSO-NETO, V.; BARTORELLI, A.; CARNEIRO, C.D.R.; BRITO NEVES, B.B. (eds.) Geologia do Continente Sul-Americano: evolução da obra de Fernando Flávio Marques de Almeida. São Paulo: Beca, 2004. p.383-405.

RIYIS, M. T. et al. Investigação de áreas contaminadas com elaboração do modelo conceitual em campo utilizando ferramentas de alta resolucão (HRSC). Revista Brasileira de Geologia de Engenharia e Ambiental, v. 3 , n. 1, p. $125-137,2013$.

SANTOS; R. D et al. Manual de descrição e coleta de solo no campo. 5. ed. revisada e ampliada. Viçosa: Sociedade Brasileira de Ciência do Solo, 2005. 100 p.

SCHULMEISTER, M. K. et al. Direct-push electrical conductivity logging for high-resolution hydrostratigraphic characterization. Ground Water Monitoring \& Remediation, v. 23, n. 3, p. 52-62, 2003.

SERVMAR SERVIÇOS TÉCNICOS AMBIENTAIS - SERVMAR. Relatório de Investigação Detalhada, Avaliação de Risco à Saúde Humana e Plano de Intervenção na Al-01 e Investigação Detalhada de Gases. Relatório MA/12936/14/BLS.São Paulo, SP. 2014.

UNITED STATES ENVIRONMENTAL PROTECTION AGENCY - USEPA. Chapter V: Direct Push Technologies. In: Expedited Site Assessment Tools for Underground Storage Tank Sites: A Guide for Regulators.[s.I: s.n.]. 2016. Disponivel

<https://www.epa.gov/sites/production/files/2014-

03/documents/esa-ch5.pdf>. Acesso em: 16 dez. 2016.

VARNIER, C.; HIRATA, R. Contaminação da água subterrânea por nitrato no Parque Ecológico do Tietê - São Paulo. Águas Subterrâneas, São Paulo, v. 16, n. 1, p. 77-80, 2002.

WILSON, J. T.; ROSS, R. R.; ACREE, S. Using direct-push tools to map hydrostratigraphy and predict MTBE plume diving. Ground Water Monitoring \& Remediation, v. 25, n. 3, p. 93-102, 2005. 